\title{
Aktivitas Komunikasi Pemasaran Melalui Akun Instagram (Studi Pada Staff dan Pengelola Akun Pelindo Daya Sejahtera)
}

\author{
Marissa Ono Damayanti ${ }^{1 *}$, Widiya Yutanti ${ }^{2}$ \\ 1,2 Program Studi Ilmu Komunikasi, Universitas Muhammadiyah Malang, Kota \\ Malang, Provinsi Jawa Timur, Indonesia.
}

\begin{abstract}
Abstrak. Era modern saat ini dan ditengah pelik pandemi Covid-19 setiap perusahaan dituntut untuk. berfikir kreatif dan inovatif dimana media sosial sangatlah berperan penting dalam kegiatan komunikasi pemasaran salah satunya media sosial Instagram sebagai salah satu cara untuk melakukan Aktivitas Komunikasi Pemasaran. Dengan menggunakan metode pendekatan kualitatif dengan jenis penelitian deskriptif. Serta menggunakan teknik pengumpulan data wawancara, dokumentasi dan studi pustaka. Didukung dengan pendekatan teori perencanaan yang merupakan salah satu model penyusunan pesan yang dilakukan untuk mencapai tujuan komunikasi pemasaran. Hal ini dapat disimpulkan bahwa semakin baik komunikasi pemasaran yang dilakukan dengan pemanfaatan prinsip Marketing mix 4P melahi media sosial Instagram, maka akan memiliki dampak pula pada efektivitas promosi dan target pengelola maupun staff akan terpenubi.
\end{abstract}

Kata kunci: Outsourcing; Humas; Kualitatif.

Abstract. In the current modern era and in the midst of the complicated Covid-19 pandemic, every company is required to think creatively and innovatively where social media plays an important role in marketing communication activities, one of which is Instagram social media as a way to carry out Marketing Communication Activities. By using a qualitative approach with the type of descriptive research. And using interview data collection techniques, documentation, and literature study. Supported by a planning theory approach which is one of the models for compiling messages to achieve the goals of marketing communications. It can be concluded that better marketing communication is carried out by utilizing the 4P Marketing mix principle through Instagram social media, it will also have an impact on the effectiveness of promotions and the targets of managers and staff will be met.

Keywords: Outsourcing; Public Relations; Qualitative.

Copyright @ 2022. Published by Lembaga Otonom Lembaga Informasi dan Riset Indonesia (KITA INFO dan RISET). 


\section{Pendahuluan}

Di era modern saat ini dan ditengah pelik pandemi Covid-19 setiap perusahaan dituntut untuk berfikir kreatif dan inovatif dimana media sosial sangatlah berperan penting dalam kegiatan komunikasi pemasaran salah satunya media sosial Instagram sebagai salah satu cara untuk memberikan informasi serta memenuhi kebutuhan masyarakat saat ini yang tidak bisa lepas dari sebuah ingin ketahuan akan sebuah informasi. Dan rasa keingin tahuan penelitian yang ingin mengetahui Apa saja aktivitas komunikasi pemasaran yang dilakukan oleh Pelindo Daya Sejahtera.

Dilihat dari peningkatan akses media sosial dari tahun 2020 ke tahun 2021 yang awalnya pengguna media sosial aktif sebesar 160 juta meningkat menjadi 170 juta. Dan sosial media yang peringkatnya mengalami perubahan dimana pada tahun 2020 Top 3 ditempati Youtube, Whatsapp dan Facebook di tahun 2021 berubah dan bergeser menjadi Youtube, Whatsapp dan Instagram dimana media sosial milik Mark Zuckerberg selama dua tahun ini tetap mendominasi teratas 3 besar sosial media yang diakses 170 juta pengguna media sosial aktif menurut tekno kompas.

Pelindo Daya Sejahtera sendiri merupakan salah perusahaan yang bergerak di bidang jasa outsourching dimana perusahaan tersebut diletak di kota Surabaya. Aktivitas komunikasi pemasaran yang dilakukan oleh Pelindo Daya Sejahtera dengan memanfaatkan berbagai cara seperti promosi melalui Facebook, Twitter, Website serta akun media sosial yang paling mudah diakses dan paling up-to-date ialah media sosisal Instagram dibanding dengan akun media sosial lain seperti Facebook maupun Twitter. Akun Instagram@pelindodayasejahtera dan saat ini memiliki 26 ribu pengikut (Januari 2022). Pengguna akun Instagram oleh Pelindo Daya Sejahtera digunakan untuk keperluan kegiatan komunikasi pemasaran guna memberikan informasi jasa pelayanan yang ditampilkan dengan foto maupun video. Terlebih lagi dengan adanya fitur hastag maupun share story yang memudahkan pengguna lain untuk menemukan informasi yang dibutuhkan. Dengan adanya persaingan antara perusahaan outsourching yang ada di kota Surabaya maka perlu adanya kegiatan komunikasi pemasaran online yang harapannya dapat memberikan kemudahan terhadap target pasar yang lebih luas dan memberikan informasi terhadap calon konsumen dan masyarakat yang ingin mengetahui lebih banyak tentang perusahaan. Peneliti akan membahas aktivitas komunikasi pemasaran online Pelindo Daya Sejahtera pada media sosial Instagram. Fokus penelitian ini akan mendeskripsikan tentang aktivitas komunikasi pemasaran online yang dilakukan Pelindo Daya Sejahtera melalui media akun Instagram@pelindodayasejahtera.

\section{Tinjauan Literatur}

\section{Komunikasi Pemasaran}

Komunikasi pemasaran adalah sebuah proses dalam penyampai informasi terhadap khalayak agar pengetahuan mengenai produk tepat sasaran terutama bagi calon konsumen maupun masyarakat yang ingin mengetahui tentang produk sebuah perusahaan. Kegiatan komunikasi pemasaran sendiri mempunyai tujuan untuk mencapai target yang ingin dicapai seperti: 1) memasang sebuah iklan (beriklan) dimedia massa (media advertising) seperti cetak ataupun online maupun suara; 2) sebagai bentuk pemasaran langsung (direct marketing); 3) sebagai sarana berjualan maupun promosi (sales promotion); 4) dan penjualan yang dilakukan secara personal (personal selling); 5) sebagai bentuk pemasaran interaktif; 6) sebagai jalinan hubungan masyarakat (public relations) dan untuk mencapai sebuah komunikasi yang lebih efektif (Morisan, 2010). Strategi komunikasi pemasaran sendiri berasal dari konsep sederhana yaitu bagaimana pengembangan strategi pemasaran secara makro dan bergantung pada bagaimana strategi yang dikatitkan dengan perencanaan bisnis perusahaan tersebut. Dengan jelas bahwa komunikasi perusahaan sendiri mengarah pada visi misi perusahaan dalam mencapai tujuan mereka kedepannya.

\section{New Media Dalam Ilmu Komunikasi}

Karakterisitik dari new media yang bisa membuat seseorang terpikat, termanipulasi maupun secara interaktif diakses adalah sebagai bentuk efek dari sebuah kemajuan dari sebuah teknologi komunikasi yang muncul. Ditambah juga dengan hadirnya sebuah internet sebagai media baru yang jelas dapat memberikan efek 
secara tidak langsung terhadap pola sosial yang ada didalam kehidupan dikalangan masyarakat. Pada akhirnya secara tidak langsung memberikan efek yang baik secara langsung maupn tidak langsung (Nasrullah, 2018). Menurut Van Dijk, 2013 (dalam Nasrullah, 2018) media sosial sendiri merupakan sarana online yang bisa memberikan eksistensi dan menggambarkan keinginan seseorang dengan sebuah kegiatan yang tampilkan dalam sebuah visual. Media sosial sendiri dapat sebagai wadah atau perantara berbentuk digital dengan menghubungkan antara user sekaligus menjalin sebuah pertemanan secara nurani dengan orang lain. Dalam penelitian ini media sosial berarti merupakan sebuah wadah yang bisa memberika segala informasi, yang memungkinkan penggunanya bisa saling berbagi, serta melakukan interaksi satu sama lain sesama pengguna media online, maupun dalam membangun relasi dengan memanfaatkan platform yang telah disediakan oleh media sosial dan jaringan internet.

Aplikasi instagram sendiri adalah media perantara untuk membagikan sebuah moment kepada user lain, tidak hanya sebatas gambar melainkan antar penggunapun bisa saling menukarkan informasi pribadi melalui ketikan dan saling bertukar pesan satu sama lain dimana pesan tersebut merupakan sebuah fitur yang telah disediakan. Instagram merupakan sebuah aplikasi media sosial yang terdapat di smartphone yang support untuk mendownload aplikasi tersebut. Berdasarkan Data Statistik User Instagram di Indonesia, Instagram termasuk kedalam kategori aplikasi aktif yang ada di Indonesia yang sedang naik daun dengan mengalami peningkatan secara signifikan dari tahun ke tahun (Januari 2017). Hasil tersebut diambil dari DRPPI (Data Riset Perilaku Pengusaha Indonesia) dimana akun Instagram sendiri sebanyak 53\% akun dikelolah oleh badan milik usaha yang ada di Indonesia akun lain yang bergerak di bidang perekonomian food and beverages sebesar $21 \%$ akun ditempati oleh industri farmasi, maupun bidang beauty and bealthy sebesar 17\% dari industri busana. Serta total perusahaan yang sudah menginstall aplikasi serta dalam kurun waktu 2-3 tahun terakhir memperoleh presentase sebesar 33\%. (APJII, 2018).

\section{Instagram}

Instagram sendiri merupakan aplikasi yang memiliki tujuan sebagai media sharing, yang termasuk kedalam jenis media yang memberikan fasilitas bagi penggunanya dalam berbagi informasi. Dari pemanfaatan dari aplikasi Instagram itu sendiri merupakan media sosial yang cocok untuk sebagai media pemasaran yang didalamnya bisa menampilkan segala bentuk informasi yang dapat dikonsumsi khalayak serta memberi wadah untuk menambah ilmu pengetahuan yang bisa dicerna dan dipilah oleh khalayak di dalam masyrakat dimana mereka bisa melihat maupun mengakses. Dan calon konsumen maupun calon tenaga alih daya yang merupakan stakeholder yang berpengaruh dalam berjalanya perusahaan Pelindo Daya Sejahtera bisa memberikan segala informasi serta pelayanan jasa yang dapat ditawarkan oleh perusahaan melalui media sosial Instagram.

\section{Metodologi Penelitian}

Peneliti menggunakan pendekatan penelitian kualitatif deskriptif dirasa sangat tepat, karena pendeketan tujuan awal untuk menjukkan dan memberikan gambaran bagaimana komuniksi pemasaran yang dilakukan Pelindo Daya Sejahtera melalui media sosial Instagram. Yaitu penelitian yang berisikan hasil data yang disatukan dan diwujudkan dalam bentuk tulisan, serta menampilkan sebuah gambar, serta tidak menggunakan angka. Hasil data yang telah diperoleh akan dikelola menjadi sebuah pedoman untuk mengecek tentang penelitian yang sedang diteliti. (Moleong, 2005). Demikianlah, diperoleh hasil penelitian kualitatif yang berisikan kutipan-kutipan data serta kata-kata dimana dipresentasikan kedalam media sosial instagram Pelindo Daya Sejahtera dalam melakukan kegiatan proses komunikasi pemasaran perusahaan. Dengan menggunakan metode wawancara mendalam (indepth interview) dengan konsep pertanyaan $5 \mathrm{~W}+1 \mathrm{H}$ dengan menggunakan pertanyaan seperti apa (what), siapa (who), mengapa (why), kapan (when), di mana (where) dan bagaimana (bow) yang nantinya digunakan kedalam draft wawancara yang bertujuan untuk memperoleh gambaran yang memadai dan akurat mengenai aktivitas komunikasi pemasaran. Dokumen 
yang digunakan ialah data-data mengenai fitur Instagram yang ada di akun media sosial @ pelindodayasejahtera. Validitas dalam penelitian ini dilakukan dengan teknik validitas tringulasi data atau tringulasi sumber, yakni teknik pemeriksaan keabsahan data yang memanfaatkan data dari sumber dengan mengecek dari sumber lain atau sebagai perbandingan sebuah data. Artinya data yang sama ataupun sejenis, akan lebih akurat kebenarannya apalagi digali dari sumber yang berbeda.

Dengan penelurusan data yang bersumber dari staff dan pengelola akun media sosial Instagram "pelindodayasejahtera" Narasumber Utama Regina Bestrya dan Narasumber Pendukung Vemma Novitasari dan Try Aditio Kusuma yang merupakan staff dan pengelola akun itu sendiri. Dimana aktivitas komunikasi pemasaran ditampilkan dalam wujud aplikasi dan di upload kedalam akun Instagram yang sudah memiliki verifikasi. Dengan pengambilan sampel untuk subyek penelitian dengan menggunakan purposive sampling berdasarkan beberapa kriteria tsubjek yang sesuai dengan kebutuhan peneliti yaitu (a) Merupakan Karyawan tetap dari Pelindo Daya Sejahtera, (b) Pernah menjabat sebagai staff humas, (c) Pernah mengelola akun @ pelindodayasejahtera, (d) Bagian yang terlibat dalam proses maupun aktivitas komunikasi pemasaran.

\section{Hasil dan Pembahasan}

Berdasarkan penelitian yang telah dilakukan diketahui bahwa segala kegiatan aktivitas komunikasi pemasaran yang dilakukan oleh Pelindo Daya Sejahtera melalui media sosial instagram dengan memanfaatkan Indikator marketing mix 4P. Dapat disimpulkan bahwa semakin baik aktivitas komunikasi pemasaran yang dilakukan melalui media sosial instagram maka akan semakin baik pula efektivitas yang dapat dirasakan oleh perusahaan dan sudah memenuhi 4 indikator yang disarankan (Linggar, 2000). Dimana segala aktivitas komunikasi pemasaran memiliki tujuan dalam mengenalkan dan memberikan citra tersendiri bagi stakeholder maupun masyarakat tentang perusahaan tersebut.

\section{Aktivitas Komunikasi Pemasaran Pelindo Daya Sejahtera Pada Media Sosial Instagram@pelindodayasejahtera}

Pelindo Daya Sejahtera merupakan salah perusahaan yang bergerak di bidang jasa outsourching yang bergerak di bidang jasa pelayanan. Media sosial sendiri bukan hal yang kuno terutama media sosial Instagram itu sendiri seperti yang diutarakan oleh Regina Bestrya dalam wawancara singkatnya ia berkakata bahwa media sosial sendiri saat ini memberikan efek besar di bidang komunikasi dimana salah satunya media sosial Instagram sebagai salah satu media publikasi yang mereka gunakan saat ini. Karena tidak dapat dipungkiri media sosial Instagram merupakan media komunikasi pemasaran yang tidak bias dianggap remeh karena kebanyakan masyarakat usia produktif pasti memiliki akun Instagram dan dalam mendukung komunikasi pemasaran dan perusahaan yang bergerak dibidang jasa akan mudah bagi masyarakat yang sekedar ingin mengetahui informasi maupun menjadi bagian salah satu tenaga SDM (Sumber Daya Manusia) yang merupakan bagian penting dalam layanan tenaga alih daya yang disediakan oleh Pelindo Daya Sejahtera itu sendiri. Kegiatan publikasi maupun promosi tidak lepas dari penggunaaan media Instagram agar masyarakat dapa lebih mengenal tentang produk maupun perusahaan. Segala kegiatan mulai dari pengenalan produk maupun, kegiatan afiliasi dan kerjasama antar perusahaan dan segala kegiatan lain pasti di informasikan terhadap masyarakat maupun calon konsumen. Penggunaan resolusi foto dan video unggahan pun tidak boleh menggunakan resolusi rendah agar informasi yang ingin disampaikan bias diterima oleh followers dari akun@pelindodayasejahtera itu sendiri dengan jelas dan benar. Instagram juga menyediakan fitur biglights agar informasi tertentu tidak tenggelam dan tertimbun oleh konten-konten baru.

\section{Aktivitas Komunikasi Pemasaran Online (a) pelindodayasejahtera melalui Instagram}

1) Upload Foto dan Video Konten

Saat ada konten yang akan di upload makan pengelola akun akan mengunggah foto maupun video di akun media sosial Instagram. Agar komunikasi pemasaran bisa berjalan dengan baik maka Try Aditio 
Kusuma sebagai pengelola akun akan mengupload foto atau video sesuai dengan kebutuhan kebutuhan komunikasi pemasaran perusahaan dimana konten tersebut sebelumnya sudah melewati tahap diedit guna menarik perhatian followers agar terlihat berbeda dengan perusahaan lainnya.

\section{2) Proses Interaksi}

Setelah melakukan tahap unggah foto \& video untuk kebutuhan konten makan informasi yang akan ditampilkan belum termasuk harga maka digunakanlah fitur caption yang berguna untuk memberikan informasi lanjutan tentang konten tersebut. Karena informasi tentang harga memang tidak ditampilkan di media sosial Instagram dan oleh karena itu calon konsumen akan diarahkan ke media lain yaitu Whatsapp maupun Email guna melakukan interaksi langsung dengan pihak marketing agar mempermudah pengawasan proses komunikasi pemasaran yang sedang berlangsung. Whatsapp sendiri adalah aplikasi media sosial untuk sarana interaksi bisnis yang memberikan kemudahan untuk pelaku bisnis dalam mengkomunikasikan aktivitas pemasaran.

\section{Analisa Aktivitas Komunikasi Pemasaran Online Pelindo Daya Sejahtera pada media sosial Instagram}

Dari data diatas peneliti juga menganalisis aktivitas komunikasi pemasaran online Pelindo Daya Sejahtera yang dilakukan melalui media sosial Instagram@pelindodayasejahtera menggunakan prinsip marketing mix yang terdiri dari produk, harga, promosi dan tempat (product, price, promotion and place) atau biasa dikenal dengan 4P marketing communication menurut (Linggar,2000).

\section{1) Product}

Yaitu aktivitas komunikasi pemasaran yang berkaitan dengan sebuah produk yang berhubungan dengan jenis layanan maupun jasa yang disediakan oleh Pelindo Daya Sejahtera seperti layanan tenaga alih daya, layanan asesmen maupun konsultasi, dan layanan pemeliharaan fasilitas.

Pelindo Daya Sejahtera memberikan solusi terhadap pelanggan yang ingin menemukan tenaga alih daya sesuai dengan kebutuhan dan sesuai yang mereka mau merupakan salah satu bentuk Customer Solutions yang terdapat di dalam Communication Mix. Produk jasa yang diberikan oleh Pelindo Daya Sejahtera memiliki verifikasi bidang professional menurut keahlian masingmasing dimana jasa yang ditawarkan dan mempunyai karakter 5 Prima PDS yaitu Senyum, Salam, Sapa, Terima Kasih dan Harapan.

2) Price

Setiap perusahaan tentu saja menawarkan yang namanya harga seperti Pelindo Daya Sejahtera yang memberikan penawaran harga sesuai dengan Comply UU Ketenaga Kerjaan dimana untuk menarik perhatiaan serta keingin tahuan calon konsumen harga tersebut tidak ditampilkan di media sosial Instagram. Sehingga dalam tranksaksi agar terjalin kegiatan komunikasi antar calon konsumen dan tim marketing yang akan memberikan informasi lebih detail tentang permasalahan harga. Penentuan harga yang dipengaruihi oleh Undang-undang memberikan nilai plus karena harga yang diberikan sesuai dengan standart UMR dan menyeimbangkan antara jasa yang diberikan dan kualitas yang akan diterima oleh calon konsumen yang menggunakan jasa pelayanan dari Pelindo Daya Sejahtera. Instagram disni memberikan fasilitas untuk interaksi dan menanyakan infomasi detail melalui aplikasi lain untuk memisahkan antara kebutuhan recruitment dan calon konsumen website resmi yang telah disediakan agar menghindari pesan tak terbalas atau tertimbun oleh notifikasi lain seperti notifikasi suka dan komentar yaitu https://www.ptpds.co.id/rekrutmen/main/ index.php dan untuk calon konsumen bisa menghubungi bagian marketing 0811-3311711 atau email marketing @ptpds.co.id.

\section{3) Place}

Melakukan bisnis dengan menggunakan media online memang hal yang mudah untuk dilakukan dan setiap orang dan hampir semua kalangan dapat melakukan kegiatan bisnis melalui media online seperti media sosial Instagram dan tidak memperlukan tempat dikarenakan harganya yang mahal. 
Kemudahan dalam kegiatan berbisnis pun sering terjadi itu kenapa banyaknya hadir Online Shop maupun perusahaan E Commerce sering kali dijadikan ajang untuk penjualan secara asal-asalan atau sebagai ajang penipuan. Karena itu sebagian pembeli sudah tidak mempercayai transaksi bisnis online.

Dengan kegiatan komunikasi pemasaran inillah Pelindo Daya Sejahtera memberikan fitur Hastag yang berguna untuk menyebarkan informasi terkait tentang perusahaan. Selain itu fungsi tagar berguna untuk mengkategorikan dalam pencarian di media sosial. Konsumen dapat menemukan produk maupun akun yang ingin mereka cari, contoh tagar yang digunakan oleh Pelindo Daya Sejahtera semisal dalam menyerukan kampanya \#TolakPungli agar para karyawan maupun calon konsumen dan followers bias melakukan pencarian yang ingin mereka temukan melalui tagar tersebut.

\section{4) Promotion}

Promosi merupakan salah satu bagian dari rangkaian aktivitas komunikasi pemasaran oleh Pelindo Daya Sejahtera. Promosi adalah suatu kegiatan bidang marketing yang didalamnya terdapat kegiatan komunikasi yang dilaksanakan biasanya bertujuan untuk pemberitaan, membujuk, dan mempengaruhi segala sesuatu mengenai produk maupun jasa yang dihasilkan untuk konsumen, segala kegiatan itu bertujuan untuk meningkatkan volume penjualan dengan menarik minat konsumen dalam mengambil keputusan untuk menggunakan pelayanan Pelindo Daya Sejahtera. Tingginya pengguna media sosial menjadi pasar yang menjanjikan bagi para pelaku usaha untuk memasarkan produknya. Pemasaran melalu media online semakin populer sejalan dengan perkembangan teknologi dan informasi yang memungkinkan informasi yang disampaikan menjangkau pasar yang lebih luas tanpa adanya batasan geografis. Selain komunikasi pemasaran yang dilakukan secara online melalui media sosial dapat menekan biaya iklan dan promosi secara signifikan sehingga lebih murah. Salah satu aktivitas komunikasi pemasaran yang dilakukan ialah mengikuti kegiatan Job Fair, Door-to-door sebelum pandemic Covid maupun Blasting Email sebaga bentuk perkenalan perusahaan.

\section{Kesimpulan}

Berdasarkan hasil dari penelitian dilakukan oleh peneliti untuk menjawab rumusan masalah bagaimana Komunikasi Pemasaran yang dilakukan Pelindo Daya Sejahtera untuk membangun company branding melalui akun instagram yang dilakukan oleh Pengelola Akun Media Sosial@pelindodayasejahtera, dapat disimpulkan bahwa komunikasi pemasaran yang dilakukan oleh Pelindo daya Sejahtera sesuai dengan indikator marketing mix $7 \mathrm{P}$ barupa product, place, price, promotion, process, physical environment dan people. Berdasarkan hasil studi pustaka dapat dikatakan bahwa pemanfaatan prinsip Marketing mix 7P dalam membangun corporate branding image Pelindo Daya Sejahtera Surabaya telah memenuhi 7 indikator yang disarankan Kotler \& Amsteong (2012:92) namun masih tidak diterapkan secara maksimal.

Peneliti dapat menyimpulkan jika Pelindo Daya Sejahtera bisa menggunakan prinsip $7 \mathrm{P}$ ini secara maksimal maka keinginan dari pengelola akan terpenuhi teruma di beberapa indikator berikut mulai dari (1) Product selain menonjolkan layanan tenaga kerja seharusnya pengelola akun bisa sesekali memberikan informasi tambahan tentang layanan lain yang disediakan semisal asesmen, pelatihan dan konsultasi agar followers dan calon konsumen bisa mendapatkan kemudahan dalam mengakses informasi layanan lain selain Layanan tenaga kerja dan Layanan Pemeliharaan Fasilitas. (3) Price bisa memberikan akses khusus untuk mengetahui harga pelayanan tenaga alih daya layanan lain secara ter up-to-date. (4) Promotion selain mengikuti kegiatan Job Fair, Blasting Email dan door-to-door seharusnya ada promosi lain yang bisa dimanfaatkan semisal memanfaatkan media lain seperti televise, Koran, Majalah dan media iklan online lain untuk lebih mengenalkan Pelindo Daya Sejahtera secara luas dan bisa memberikan efek ke pasar Non-Captive. 


\section{Daftar Pustaka}

Anang, F. (2019). Pemasaran Produk dan Merek (Planning \& Strategy). Surabaya: Qiara Media.

APJII, \& Indonesia, P. (2018, April Rabu). Assosiasi Penyelenggara Jasa Internet Indonesia. Retrieved from Survey Internet APJII 2018: https://apjii.or.id/survei2018

Butterick, K. (2014). Pengantar Public Relations. Jakarta, PT Raja Grafindo Persada.

Cangara, H. (2013). Perencanaan dan strategi komunikasi. Jakarta: PT. Raja Grafindo Persada.

Daga, R. (2017). Citra, Kualitas Produk, dan Kepuasan Pelanggan. Global Research And Consulting Institute.

Doembana, I., Rahmat, A., \& Farhan, M. (2017). Buku Ajar Manajemen dan Strategi Komunikasi Pemasaran. Yogyakarta: ZAHIR Publishing.

Gassing, \& Suryanto. (2016). Public Relations. Yogyakarta: Andi Offset.

Kotler, P., \& ARMSTRONG, G. (2012). Principles of marketing. Princípy marketingu].

Kotler, P., \& Keller, K. L. (2009). Manajemen pemasaran. Jakarta: Erlangga.

Kotler, P., Keller, K. L., Ang, S. H., Tan, C. T., \& Leong, S. M. (2021). Marketing management: an Asian perspective. Boston: Pearson.
Krisyantono, R. (2008). Public Relations Writing: Teknik Produksi Media Public Relations dan Publisitas Korporat. Jakarta: Prenadamedia.

Littlejohn, S. W., \& Foss, K. A. (2009). Teori Komunikasi (e9). Jakarta Selatan: Salemba Humanika.

Lubawan, G. S. (2014). Aktivitas Komunikasi Pemasaran Steeze. Ltd (Studi Deskriptif Kualitatif Aktivitas Komunikasi Pemasaran Steeze. Ltd Melalui Sosial Media Facebook dan Twitter).

Linggar Anggoro, M. (2005). Teori \& Profesi Kehumasan. Jakarta: Bumi Aksara.

Marentek, M., Supit, V., \& Mandey, N. (2020). Komunikasi Pemasaran. Sulawesi Utara: Polimdo Press.

Morrisan, M. A. (2015). Periklanan komunikasi pemasaran terpadu. Kencana.

Morissan, M. A. (2008). Strategi Menjadi Humas Profesional. Jakarta: Prenada Media Group.

Moleong, L. J. (2021). Metodologi penelitian kualitatif. PT Remaja Rosdakarya.

Panuju, R. (2019). Komunikasi pemasaran: pemasaran sebagai gejala komunikasi komunikasi sebagai strategi pemasaran. Prenada Media.

Pratama, A. P. (2018). Aktivitas Komunikasi Pemasaran Online Hexaimages Surabaya (Studi Deskriptif Kualitatif Mengenai Aktivitas Komunikasi Pemasaran Online Instagram@ Hexaimages). 
Rulli, N. (2017). Media Sosial Perspektif Komunikasi, Budaya, dan Sosioteknologi. Bandung: Rekatama.

Stephanie, C. (2021, Oktober Kamis). Berapa Lama Orang Indonesia Akses Internet dan Medsos Setiap Hari? Retrieved from Kompas.com:

https://tekno.kompas.com/read/2021/0 2/23/11320087/berapa-lama-orangindonesia-akses-internet-dan-medsossetiap-hari?page $=$ all
Sugiyono. (2018). Metode Penelitian Kualitatif. Bandung: Alfabeta.

Sutisna. (2002). Perilaku Konsumen dan Komunikasi Pemasaran. Bandung: Remaja Rosdakarya. 